\title{
Pengaruh Penambahan Abu Terbang (Fly Ash) terhadap Sifat Mekanik (Kuat Tekan) Semen Polimer Menggunakan Matriks Resin Epoksi
}

\author{
Oleh: \\ Abdul Rais ${ }^{1)}$ dan Juniati Berlian Sitohang ${ }^{2)}$ \\ ${ }^{1)}$ Dosen Jurusan Fisika FMIPA Unimed \\ ${ }^{2)}$ Mahasiswa Prodi Fisika FMIPA Unimed
}

\begin{abstract}
Abstrak
Tulisan ini merupakan sebuah laporan penelitian yang bertujuan untuk mengetahui pengaruh penambahan abu terbang (fly ash) dan resin epoksi terhadap sifat mekanik, dalam hal ini kuat tekan beton semen polimer dan megetahui komposiis optimal antara abu terbang Dan resin epoksi dalam pembuatan beton semen polimer.

Hasil penelitian menunjukkan bahwa nilai kuat tekan yang dihasilkan pada setiap benda uji bervariasi berkisar antara 10 - 24 Mpa . Dari hasil penelitian diperoleh bahwa penambahan bahan campuran abu terbang dan resin epoksi akan menghasilkan kekuatan tekan beton yang lebih besar dibandingkan dengan kuat tekan beton norma. Pada penambahan abu terbang dan resin epoksi dengan komposisi resin epoksi sebanyak 50\% dan abu terbang sebanyak $100 \%$ menghasilkan kekuatan tekan optimal yaitu $24 \mathrm{Mpa}$. Pada penambahan abu terbang dan resin epoksi akan menghasilkan kekuatan tekan yang lebih besar dibandingkan dengan beton normal yang memiliki kekuatan tekan sebesar 6,4 MPa.
\end{abstract}

Kata Kunci : Abu Terbang (fly ash), Resin Epoksi, Kuat Tekan.

\section{Pendahuluan}

Perkembangan teknologi design rekayasa bahan konstruksi semakin pesat. Hampir $60 \%$ material yang digunakan dalam pekerjaan konstruksi adalah beton (concrete) yang dipadukan dengan baja (komposit) atau jenis lainnya. Konstruksi beton dapat dijumpai dalam pembuatan gedung-gedung, jembatan, jalan, bendungan, saluran air, dan lain-lain. Beton merupakan salah satu pilihan sebagai bahan struktur dalam konstruksi bangunan.

Beton merupakan suatu bahan komposit (campuran) dari beberapa material, yang bahan utamanya terdiri dari medium campuran antara semen, agregat halus, agregat kasar, air, serta bahan tambahan lain dengan perbandingan tertentu. Karena beton merupakan komposit, maka kualitas beton sangat tergantung dari kualitas masingmasing material pembentuk. Inovasi teknologi beton selalu dituntut guna menjawab tantangan akan kebutuhan. Beton yang dihasilkan diharapkan mempunyai kualitas tinggi meliputi kekuatan dan daya tahan tanpa mengabaikan nilai ekonomis.

Peningkatan mutu beton dapat dilakukan dengan memberikan bahan ganti atau bahan tambah. Bahan-bahan limbah disekitar 
lingkungan dapat dimanfaatkan sebagai bahan tambahan dalam campuran beton. Hal tersebut dapat memberikan alternatif untuk mengoptimalkan pemanfaatan limbah abu terbang (fly ash) yang secara mekanik akan mengisi ruang kosong diantara butir-butir semen dan dapat memperkecil volume pori pada beton.

Abu terbang (fly ash) adalah sisa hasil proses pembakaran batubara yang keluar dari tungku pembakaran berbutir halus dan bersifat pozolanik. Abu terbang ini dapat berasal dari limbah industri Pembangkit Listrik Tenaga Uap (PLTU) dan limbah bahan bakar mesin-mesin pabrik. Mengingat limbah tersebut meningkat setiap tahunnya, maka perlu penanggulangan dan pemanfaatannya. Limbah abu terbang (fly ash) dapat mengakibatkan pencemaran lingkungan apabila tidak dimanfaatkan. Oleh sebab itu diupayakan agar abu terbang menjadi bahan yang berguna, antara lain pemanfaatan abu terbang (fly ash) sebagai campuran beton dan dapat bernilai ekonomis..

Dermawan

mengemukakan bahwa pengujian kuat tekan dan pengujian kuat tarik batako dengan pencampuran abu terbang (fly ash) dimana pada penambahan abu terbang (fly ash) sebagai bahan penambahan batako sebanyak 5\%, $10 \%, 15 \%$ dari berat semen menghasilkan kuat tekan rata-rata sebesar 20,66 Mpa, 24,40 $\mathrm{MPa}$, dan 18,40 $\mathrm{MPa}$ sedangkan tanpa penambahan abu terbang (fly ash) kekuatan tekan rata-rata 16,50 MPa. Sejalan dengan itu Sebayang (2006) menekankan bahwa penggantian abu terbang sebesar
$20 \%$ dari berat semen pada umur 56 hari memberikan kuat tekan optimum yaitu mencapai 55,275 MPa. Sebayang lebih lanjut mendeskripsikan hal ini dalam penelitiannya yang berjudul "Pengaruh abu terbang sebagai pengganti sejumlah semen type V pada beton mutu tinggi".

Berikutnya Siregar (2009) menemukan bahwa pemanfaatan kulit kerang dan resin epoksi terhadap karakteristik beton polimer dimana kualitas beton optimum diperoleh pada komposisi $80 \%$ (volume) serbuk kulit kerang, dan $20 \%$ (volume) resin epoksi dan nilai kuat tekan 56,9 MPa, Kuat patah 34 $\mathrm{MPa}$, kuat tarik 7,46 MPa. Dari penelitianyang dilakukan, menunjukkan adanya pengaruh abu terbang (fly ash) dan juga pengaruh resin epoksi terhadap kekuatan tekan beton semen polimer.

Berdasarkan permasalahan di atas maka penelitian ini mendeskripsikan dimana penggantian abu terbang sebesar $20 \%$ dari berat semen pada umur 56 hari memberikan kuat tekan optimum yaitu mencapai 55,275 $\mathrm{MPa}$. "Pengaruh Penambahan Abu Terbang (fly ash) Terhadap Sifat Mekanik dalam hal ini kuat tekan Beton Semen Polimer Menggunakan Matriks Resin Epoksi”.

\section{Metode Penelitian}

Penelitian ini merupakan penelitian eksperimen yang dilakukan di Laboratorium Beton USU. Pembuatan sampel dengan menambahkan fly ash dalam adukan beton diasumsikan akan mempengaruhi kuat tekan beton. pengujian kuat tekan beton yang ditambah dengan Fly ash dilakukan 
di Laboratorium Beton USU pada bulan Oktober - Desember 2011.

Alat-alat yang digunakan dalam penelitian ini adalah : Neraca, Alat-alat gelas, Cetakan beton (mould steel) yaitu cetakan kubus dengan ukuran $(5 \times 5 \times 5) \mathrm{cm}^{3}$ dan brequitte dengan ukuran $(7,5 \times 4,15$ $\mathrm{x} 2,5) \mathrm{cm}^{3}$, Mesin kompresor (compressor machine) A Macklon Smith LTD serial No.125760.7, Mesin uji tarik (Tensile test) A Macklon - Smith LTD serial No.T223/70, Ayakan screen 100 mesh, Wadah Pencampur (ember), Alat pengaduk (Mixer) Oven Pemanas (drying oven)

Sementara itu, Bahan bahan yang digunakan dalam penelitian ini adalah Semen Portland tipe I yaitu semen Portland yang diproduksi oleh PT. Semen Padang, Abu terbang (fly ash) yaitu abu terbang (fly ash) dari PLTU Labuhan Angin Sibolga, Pasir sungai yaitu pasir yang berada dari kawasan/daerah Medan, Polimer jenis resin epoksi dan hardener, Vaselin, Kerikil, Thinner

\section{Variabel penelitian}

Variabel penelitian yang digunakan dalam penelitian adalah sebagai berikut:
1. Variabel bebas

Variabel bebas adalah variabel yang menjadi sebab perubahannya atau timbulnya variabel dependen. Yang menjadi variabel bebas dalam penelitian ini adalah subsitusi abu terbang (fly ash) dan resin epoksi untuk beton semen polimer.

2. Variabel terikat

Variabel terikat merupakan variabel yang dipengaruhi atau menjadi akibat, karena adanya variabel bebas. Yang menjadi variabel terikat dalam penelitian ini adalah kuat tekan dari beton semen polimer.

3. Variabel kontrol

Variabel kontrol adalah variabel yang dikendalikan dilihat konstan sehingga peneliti dapat melakukan penelitian bersifat membandingkan. Yang menjadi variabel kontrol dalam penelitian ini adalah semen Portland tipe 1 dan massa kerikil.

\section{Analisa Data}

Data tersebut dianalisis dengan metode regresi linier berganda yaitu akan ditentukan hubungan antara $\mathrm{Y}$ dan $X_{1}, X_{2}$ sehingga didapat regresi $\mathrm{Y}$ atas $\mathrm{X}_{1}, \mathrm{X}_{2}$, selanjutnya dilakukan pengujian koefisien-koefisien regresi dan ditentukan koefisien determinasi. 


\section{Diagram Alir Penelitian}

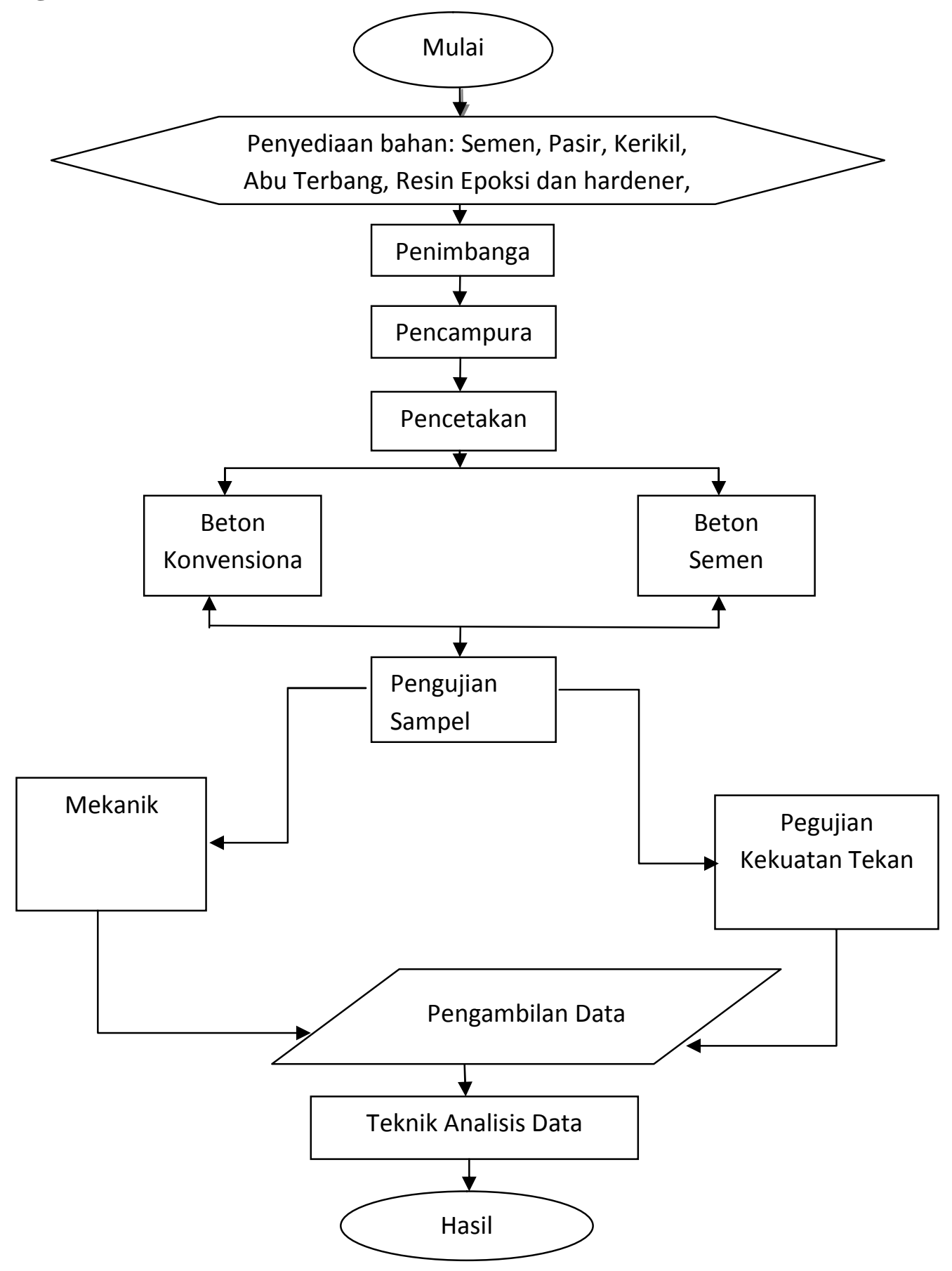

Hasil Penelitian Dan Pembahasan

\section{Hasil Penelitian}

Data hasil pengujian kuat tekan beton semen polimer dengan penambahan abu terbang (fly ash) dan resin epoksi sesuai dengan penelitian yang telah dilakukan tertera pada table berikut ini: 
Tabel Data Hasil Pengujian Kekuatan Tekan Beton Semen Polimer

\begin{tabular}{|c|c|c|c|c|}
\hline \multicolumn{2}{|c|}{$\begin{array}{c}\text { Variasi } \\
\text { Campuran }\end{array}$} & \multirow{2}{*}{$\begin{array}{c}\text { Luas } \\
(\mathbf{A}) \\
\left(\mathbf{m}^{2}\right)\end{array}$} & \multirow{2}{*}{$\begin{array}{c}\text { Beban } \\
\text { Tekan } \\
(\mathbf{F}) \\
(\mathrm{N})\end{array}$} & \multirow{2}{*}{$\begin{array}{c}\text { Kuat } \\
\text { Tekan } \\
(\sigma) \\
(\mathrm{MPa})\end{array}$} \\
\hline $\begin{array}{c}\text { Abu } \\
\text { terbang } \\
(\text { fly ash }) \\
(\%)\end{array}$ & $\begin{array}{c}\text { Resin } \\
\text { Epoksi } \\
(\%)\end{array}$ & & & \\
\hline \multirow{3}{*}{0} & 40 & 0,0025 & 25000 & 10 \\
\hline & 50 & 0,0025 & 30000 & 12 \\
\hline & 60 & 0,0025 & 30000 & 12 \\
\hline \multirow{3}{*}{25} & 40 & 0,0025 & 35000 & 14 \\
\hline & 50 & 0,0025 & 40000 & 16 \\
\hline & 60 & 0,0025 & 35000 & 14 \\
\hline \multirow{3}{*}{50} & 40 & 0,0025 & 45000 & 18 \\
\hline & 50 & 0,0025 & 45000 & 18 \\
\hline & 60 & 0,0025 & 50000 & 20 \\
\hline \multirow{3}{*}{75} & 40 & 0,0025 & 45000 & 18 \\
\hline & 50 & 0,0025 & 55000 & 22 \\
\hline & 60 & 0,0025 & 45000 & 18 \\
\hline \multirow{3}{*}{100} & 40 & 0,0025 & 60000 & 24 \\
\hline & 50 & 0,0025 & 60000 & 24 \\
\hline & 60 & 0,0025 & 55000 & 22 \\
\hline
\end{tabular}

\section{Pembahasan}

Kekuatan tekan adalah kemampuan beton untuk menerima gaya tekan per satuan luas. Nilai kekuatan tekan yang diperoleh dari setiap sampel akan berbeda, hal ini disebabkan karena beton merupakan material heterogen, yang kekuatan tekannya dipengaruhi oleh proporsi campuran, bentuk dan ukuran, kecepatan pembebanan, dan oleh kondisi lingkungan pada saat pengujian.

Dari tabel diatas diperlihatkan nilai kuat tekan yang dihasilkan pada setiap benda uji bervariasi berkisar antara 10 - $24 \mathrm{MPa}$. Dari data diatas diperoleh bahwa dengan penambahan bahan campuran abu terbang (fly ash) dan resin epoksi akan menghasilkan kekuatan tekan beton yang lebih besar dibandingkan dengan kuat tekan beton normal. Berarti semakin besar penambahan komposisi bahan campuran pada beton, maka semakin besar kekuatan tekan beton.
Dari data hasil pengujian kekuatan tekan beton dengan menggunakan bahan campuran abu terbang (fly ash) dan resin epoksi, dapat dibuat grafik hubungan antara komposisi penambahan abu terbang (fly ash) dan resin epoksi dengan kekuatan tekan beton yang terlihat dibawah ini :

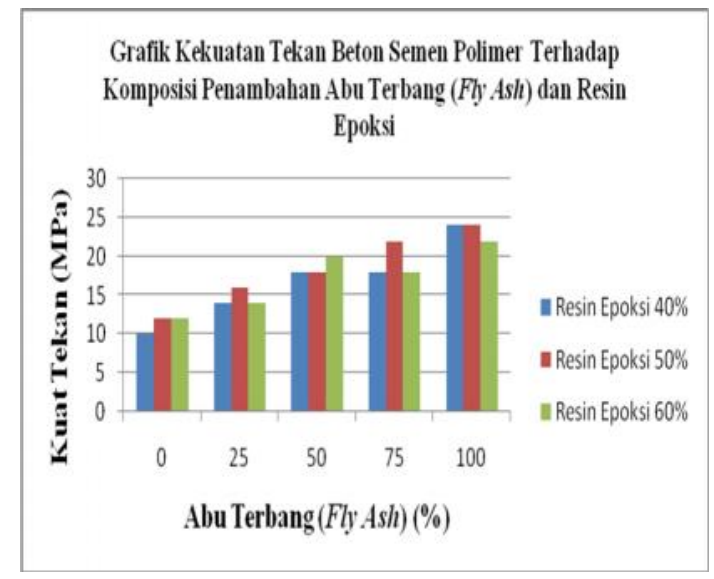

Grafik 1. Hubungan Kuat Tekan

Beton Semen Polimer Terhadap

Penambahan Abu Terbang (Fly Ash) dan Resin Epoksi

Grafik Kekuatan Tekan Beton Semen Polimer Terhadap Komposisi Penambahan Abu Terbang $(F y . A s h)$ dan $40 \%$ Resin Epoksi

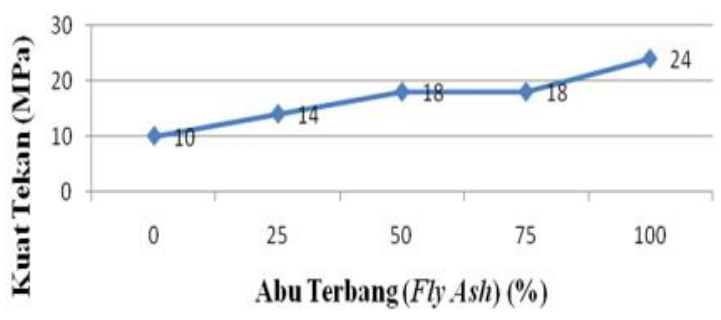

Grafik 2. Hubungan Kuat Tekan Beton Semen Polimer Terhadap Komposisi Penambahan Abu Terbang (Fly Ash) dan 40\% Resin Epoksi 
Grafik Kekuatan Tekan Beton Semen Polimer Terhadap Komposisi Penambahan Abu Terbang ( Fly Ashit dan 50\% Resin Epoksi

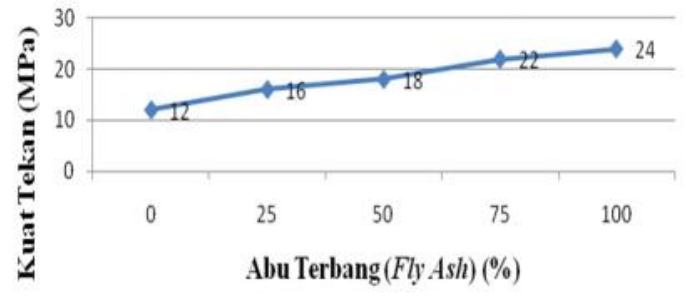

Grafik Hubungan Kuat Tekan Beton Semen Polimer Terhadap Komposisi Penambahan Abu Terbang (Fly Ash) dan 50\% Resin Epoksi

Grafik Kekuatan Tekan Beton Semen Polimer Terhadap Komposisi Penambahan Abu Terbang (Fly Ash $)$ dan $60 \%$ Resin Epoksi

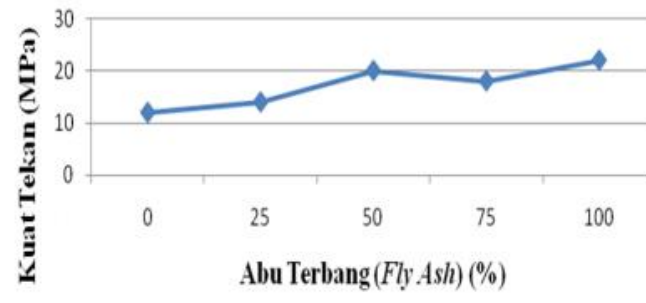

Gambar Grafik Hubungan Kuat

Tekan Beton Semen Polimer

Terhadap Komposisi Penambahan

Abu Terbang (Fly Ash) dan 60\%

Resin Epoksi

Dari gambar - gambar diatas menunjukkan bahwa adanya hubungan antara kekuatan tekan beton dengan komposisi abu terbang (fly ash) dan resin epoksi. Kemudian dilakukan uji linieritas (uji hubungan antara kekuatan tekan dengan komposisi abu terbang dan resin epoksi) sehingga didapat persamaan regresi yang diperoleh dari hasil perhitungan regresi linier ganda yaitu: $\mathrm{Y}=10,97+0,11 \mathrm{X}_{1}+0,02 \mathrm{X}_{2}$.

Dari persamaan tersebut menunjukkan bahwa adanya hubungan linier antara kuat tekan dengan komposisi abu terbang (fly ash) dan resin epoksi yang ditambahkan pada beton.

Untuk menunjukkan seberapa erat hubungan antara kuat tekan beton dengan komposisi abu terbang (fly ash) dan resin epoksi dapat dihitung dengan menggunakan rumus koefisien korelasi ganda antara ketiganya, sehingga diperoleh $\mathrm{R}=$ 0,93 yang berarti bahwa grafik diatas menunjukkan hubungan linier positif langsung antara kuat tekan beton dengan abu terbang (fly ash) dan resin epoksi.

\section{Kesimpulan}

Berdasarkan hasil penelitian dan pembahasan pengujian kekuatan tekan beton semen polimer dengan menggunakan penambahan abu terbang (fly ash) dapat disimpulkan:

1. Nilai kuat tekan yang dihasilkan pada setiap benda uji bervariasi berkisar antara 10 - $24 \mathrm{MPa}$ Pada penambahan abu terbang (fly ash) dan resin epoksi sebagai bahan penambahan beton semen polimer dengan komposisi resin epoksi sebanyak $40 \%$ dan $50 \%$ dan abu terbang (fly ash) sebanyak $100 \%$ menghasilkan kekuatan tekan maksimal masingmasing sebesar $24 \mathrm{MPa}$.

2. Penambahan abu terbang (fly ash) dan resin epoksi akan menghasilkan kekuatan tekan lebih besar dibandingkan dengan beton normal yang memiliki kekuatan tekan sebesar 6,4 Mpa Nilai kuat tekan yang diperoleh dari penelitian lebih rendah dibandingkan dengan teori, hal ini disebabkan jenis kerikil yang digunakan bersifat rapuh sehingga sifatnya melemahkan beton tersebut. 


\section{Saran}

Untuk mengetahui lebih jauh tentang pengaruh abu terbang (fly ash) dan resin epoksi terhadap kekuatan tekan beton semen polimer maka disarankan untuk:

1. Memperhatikan jenis kerikil yang dipakai saat penelitian agar diperoleh kuat tekan yang lebih optimal

2. Menambah variasi komposisi abu terbang (fly ash) dan resin epoksi untuk melihat lebih jelas pengaruh bahan tersebut terhadap kuat tekan dan kuat tarik beton.

\section{Daftar Pustaka}

A. J. Hartomo, dkk, (1989), Memahami Polimer dan Perekat, Yogyakarta, Penerbit Andi Offset,

Andoyo, (2006), Pengaruh Penggunaan Abu Terbang (fly ash) Terhadap Kuat Tekan dan Serapan Air Pada Mortar, Skripsi, UNNES, Semarang

Dermawan, Agus, (2009), Pengujian kuat Tekan dan kuat tarik Batako dengan pencampuran abu terbang (fly ash), Skripsi, Unimed, Medan.

Dorel Feldman dan Anton J.H, (1995), Bahan Polimer Konstruksi Bangunan, Jakarta , Gramedia Pustaka Utama.

Maidayani, (2009), Pengaruh Aditif Lateks dan Komposisi Terhadap Karekteristik Beton Dengan Menggunakan Limbah Padat (sludge) Industri Kertas, Tesis, USU, Medan
Mulyono, Tri, (2005), Teknologi Beton, Yogyakarta, Penerbit Andi.

Murdock, L.J dan Brook, K.M, (1991), Bahan dan Praktek Beton (alih Bahasa Stepanus Hendarko), Jakarta, Erlangga.

Nugraha, Paul dan Antoni, (2007), Teknologi Beton, Yogyakarta, Penerbit Andi.

Sebayang, Surya, (2006), Pengaruh Abu Terbang sebagai Pengganti Sejumlah Semen Tipe V Pada Beton Mutu Tinggi, Vol 6 No 2, Teknik Sipil, Bandung

Sudjana, (2005), Metode Statistika, Bandung, Penerbit Tarsito.

Surdia, Tata, dkk, (1984), Pengetahuan Bahan Teknik, Jakarta, Penerbit Pradnya Paramita, 